\title{
Estágio supervisionado e de regência na Educação Infantil: aprendendo a ensinar
}

\author{
Supervised and regent internship in Childhood Education; learning to teach \\ Pasantías supervisadas y regencia en Educación Infantil; aprendiendo a enseñar
}

Recebido: 07/11/2021 | Revisado: 14/11/2021 | Aceito: 19/11/2021 | Publicado: 28/11/2021

\author{
Eunice Brito de Souza \\ ORCID: https://orcid.org/0000-0002-3979-6291 \\ Faculdade de Alta Floresta, Brasil \\ E-mail: eunicebritodesouza6@gmail.com \\ Alice Brito de Souza \\ ORCID: https://orcid.org/0000-0001-8551-1501 \\ Faculdade de Alta Floresta, Brasil \\ E-mail: alicebritodedouza@hotmail.com
}

\begin{abstract}
Resumo
O presente trabalho visa descrever o meu percurso enquanto estagiária em duas instituições de educação pré-escolar desde o primeiro contato com as crianças até o fim do estágio e o emotivo momento da despedida das crianças. Este relatório contém um componente reflexivo bem como um componente descritivo, assim, contextualiza-se e caracterizam-se as instituições e o grupo de crianças, bem como as práticas das educadoras cooperantes e por fim relatando as experiências vividas, pois segundo Imbernón (2010) "Refletir sobre a prática educacional, mediante a análise da realidade do ensino da leitura pausada, da troca de experiências. Estruturas que tornem possível a compreensão, a interpretação e a intervenção sobre a prática”. Além da prática realizada durante o estágio para confecção deste artigo também foi realizada uma vasta pesquisa bibliográfica voltada para a educação infantil. Podese tirar o aprendizado de que o amor das crianças é incondicional e que elas estão abertas a doar e a receber muitíssimo amor, que é na escola que eles suprem o amor que lhes falta, pois a maioria das crianças do estudo possuem famílias desestruturadas por diversos motivos e que o domínio da sala de aula se conquista com postura e respeito, eles respeitam à medida que são respeitados, e acima de tudo ouvir o que o aluno tem a dizer, as crianças estão sempre querendo dizer alguma coisa e não tem ninguém para ouvir preocupado em completar as páginas do livro até o final do dia. A vida escolar do aluno não está dicotomizada da vida que este tem em casa.
\end{abstract}

Palavras-chave: Ensino; Estágio regência; Formação de docentes; Experiência.

\begin{abstract}
The present work aims to describe my career as an intern in two pre-school education institutions from the first contact with the children until the end of the internship and the emotional moment of the children's farewell. This report contains a reflective component as well as a descriptive component, thus contextualizing and characterizing the institutions and the group of children, as well as the practices of the cooperating educators and finally reporting the experiences, since according to Imbernón (2010) "Reflect on educational practice, by analyzing the reality of teaching paused reading, exchanging experiences. Structures that make it possible to understand interpret and intervene in practice". In addition to the practice carried out during the internship for the preparation of this article, there was also a vastbibliographic research focused on early childhood education. You can learn that children love is unconditional and that they are open to giving and receiving a lot of love, which is at school that they supply the love they lack, since most of the children in the study have unstructured families for several reasons and that the control of the classroom is achieved with posture and respect, they respect it as they are respected, and above all, listen to what the student has to say, children are always wanting to say something and do not have no one to hear concerned about completing the pages of the book by the end of the day. The student's school life is not dichotomized from the life he has at home.
\end{abstract}

Keywords: Teaching; Regency internship; Teacher training; Experience.

\section{Resumen}

Este artículo tiene como objetivo describir mi trayectoria como pasante en dos instituciones de educación preescolar, desde el primer contacto con los niños hasta el final de la pasantía y el momento emotivo de la despedida de los niños. Este informe contiene un componente reflexivo así como un componente descriptivo, contextualizando y caracterizando así las instituciones y el grupo de niños, niñas y adolescentes, así como las prácticas de los educadores cooperantes y finalmente reportando las experiencias vividas, como según Imbernón (2010) "Reflecting sobre la práctica educativa, analizando la realidad de la enseñanza de la lectura lenta, intercambiando experiencias. Estructuras que permiten comprender, interpretar e intervenir en la práctica ". Además de la práctica realizada durante la pasantía 
para la elaboración de este artículo, también se llevó a cabo una amplia investigación bibliográfica centrada en la educación infantil. Se puede aprender que el amor de los niños es incondicional y que están abiertos a dar y recibir mucho amor, que es en la escuela donde suplen el amor que les falta, ya que la mayoría de los niños del estudio tienen familias disfuncionales por varias razones. y que el dominio del aula se conquiste con postura y respeto, respeten como se les respeta, y sobre todo escuchen lo que tiene que decir el alumno, los niños siempre están queriendo decir algo y no tienen a nadie que los escuche preocupado por completar las páginas del libro al final del día. La vida escolar del alumno no está dicotomizada de la vida que tiene en casa.

Palabras clave: Enseñanza; Prácticas de regencia; Formación de profesores; Experiencia.

\section{Introdução}

O presente trabalho visa ressaltar a importância das atividades desenvolvidas durante o processo do Estágio Supervisionado e de Regência na Educação Infantil, desde o primeiro contato com as crianças até o fim do estágio e o emotivo momento da despedida das crianças. É imprescindível relatar o carinho dispensado pelas crianças, parte fundamental e motivacional da carreira do professor, do olhar atento que estes despertam no profissional que visa captar suas reações durante a aula ministrada. É um voltar-se para sua condição de professor, buscar encontrar em sua didática por vezes o melhor desempenho de sua função.

Corroborando (Hargreaves, 2002, p. 115), "uma inovação bem sucedida implica mais do que aperfeiçoar habilidades técnicas. Ela também estimula a capacidade de compreensão dos professores em relação às mudanças que estão enfrentando".

Assim compreende melhor porque os professores possuem condutas distintas em uma única função, os meios pelos quais recebeu a formação acadêmica e os processos de reciclagem aos quais se submetem suas metodologias e sua didática.

Não apenas por serem professores jovens na docência, mas por ser um caminho a percorrer e talvez jamais se esteja preparado diante dos inúmeros cenários que serpenteiam a vida do professor.

O conhecimento profissional consolidado mediante a formação permanente apoia-se tanto na aquisição de conhecimentos teóricos e de competências de processamento da informação, análise e reflexão crítica em, sobre e durante a ação, o diagnóstico, a decisão racional, a avaliação de processos e a Reformulação de projetos (Imbernón, 2010, p.75).

Este aprimoramento vai acontecer durante a atuação docente, quando o professor vai buscando qualificação e melhorias no desenvolvimento de suas funções, que "inclua incentivos profissionais e promoções e que tente recompensar os que se interessem por elas”. (Imbernón, 2010, p.45). Consiste na atualização dos professores com vista à ação prática. Ao abastecer-se dos conhecimentos teóricos esses geram conhecimentos práticos que levam a compreensão e a disseminação do aprendizado para a sala de aula e consequentemente para os alunos. Elementos constituídos que o estágio revela, pois é neste momento que é possível relacionar a prática com a formação acadêmica e se construir enquanto profissional, o estágio oportuniza ao futuro professor conhecer a realidade ao qual este visa estar inserido.

O estágio é de suma importância, pois quando concluído, há uma sensação de que, sem esse momento, o processo formativo não seria completo, considerando que é no estágio curricular obrigatório que se vivenciam aspectos fundamentais tais como: a vivência contínua, prolongada e por completo, que envolve os processos de cuidar e educar, o planejamento, a cultura escolar, os espaços e ambientes, os materiais, a avalição, precisando tomar decisões em função das ações a realizar e interagindo com a comunidade escolar. Assim o estágio pode se tornar um momento de reflexão no período que antecede o planejamento para o desenvolvimento do estágio na Educação Infantil e seu processo de aprendizagem.

\section{Metodologia}

Quanto à natureza é classificada como pesquisa aplicada, pois analisou um único cenário buscando responder a um problema específico, que na visão de (Prodanov \& Freitas, 2013, p. 51) a pesquisa aplicada tem como objetivo “gerar 
conhecimento para a aplicação prática, dirigidos a soluções de problemas específicos, envolvendo verdades e interesses locais".

Consecutivamente, em relação a abordagem a pesquisa se classifica como uma pesquisa qualitativa, pois demonstrou seus resultados por meio de uma análise entre o mundo real e o sujeito, sem a utilização de meios estatísticos para a apresentação dos resultados. Definida por (Prodanov \& Freitas, 2013, p. 70), "como sendo a pesquisa que tem um ambiente como fonte direta dos dados. O pesquisador mantém contato direto com o ambiente e o objeto de estudo em questão, necessitando de um trabalho mais intensivo de campo.

Não se pode interferir ou manipular os fatos. O objetivo do pesquisador é apenas o de descrevê-lo tal como ele é, refere-se ao ponto de vista dos objetivos, a pesquisa está classificada como uma descritiva, pois irá descrever determinado fenômeno, neste contexto do Estágio Supervisionado na Educação Infantil em que "os fatos são observados, registrados, analisados, classificados e interpretados sem que os pesquisadores interfiram sobre eles, ou seja, os fenômenos do mundo físico e humano são estudados, mas não são manipulados pelo pesquisador” (Prodanov \& Freitas, 2013, p. 52).

Em relação aos procedimentos técnicos de pesquisa a mesma utilizou a pesquisa bibliográfica, já que possui base teórica de base de dados e livros que fornece respaldo teórico para a estruturação do artigo, sendo assim (Lakatos \& Marconi, 2001, p.183) define a pesquisa bibliográfica como, “[...] toda bibliografia já tornada pública em relação ao tema estudado, desde publicações avulsas, boletins, jornais, revistas, livros, pesquisas, monografias, teses, materiais cartográficos, etc.[...] e sua finalidade é colocar o pesquisador em contato direto com tudo que foi escrito, dito ou filmado sobre determinado assunto [...]". "Na pesquisa bibliográfica, é importante que o pesquisador verifique a veracidade dos dados obtidos, observando as possíveis incoerências ou contradições que as obras possam apresentar” (Prodanov \& Freitas, 2013, p. 54)

Como o desenvolvimento deste artigo aconteceu em uma única sala de aula se caracteriza como estudo de caso que segundo (Gil, 2010, p. 37) "consiste no estudo profundo e exaustivo de um ou mais objetos, de maneira que permita seu amplo e detalhado conhecimento".

Por conseguinte, no que se refere à coleta de dados a pesquisa utilizou o método de observação, a liberdade adquirida ao observar permeia a intensidade em tempo real captada pelo olhar, no cenário natural, os gestos, as expressões, as falas, as atitudes são genuínas e não camufladas, ao mesmo tempo em que o desenvolvimento pode ser entendido no decorrer do processo, a cognição observada paulatinamente, também à liberdade que a convivência permite deixando de interferir nas atitudes do observado. A técnica de observação pode ser muito útil para obtenção de informações. Mais do que perguntar, podemos constatar um comportamento.

Consiste na participação real do conhecimento na vida da comunidade, do grupo ou de uma situação determinada. Nesse caso, o observador assume, pelo menos até certo ponto, o papel de um membro do grupo. O observador participante enfrenta grandes dificuldades para manter a objetividade, pelo fato de exercer influência no grupo, ser influenciado por antipatias ou simpatias pessoais e pelo choque do quadro de referência entre observador e observação (Prodanov \& Freitas, 2013, p.104).

A análise de dados dependerá dos objetivos da pesquisa. Uma análise categorial pressupõe que com base nos indicadores e índices, o pesquisador pode lançar mão dos recursos quantitativos e estatísticos para fundamentar inferências que permitam afirmações consistentes, descobertas de realidades subjacentes e interpretações fidedignas. Há diversos expedientes analíticos que podem ser utilizados para análise dos dados (Chizzotti, 2014, p. 131) 


\section{Resultados e Discussão}

\subsection{Observando a prática de planejamento}

O estágio foi realizado no PRÉ-II da Escola Municipal Juscelino Kubitscheck de Oliveira e no Berçário e Maternal do Centro de Educação Criança Feliz da cidade de Paranaíta, região norte do Mato Grosso. A escola atende alunos do Pré-escolar até o nono ano e conta com mais de 800 alunos matriculados e um quadro superior a 80 funcionários entre professores e equipe de apoio.

O primeiro contato com os professores aconteceu em setembro de 2019, onde foi possível acompanhar a elaboração do planejamento das aulas para a turma Pré-escolar II, turno vespertino. As professoras assim como todo o corpo docente estavam adequando-se a Base Nacional Comum Curricular (BNCC), portanto ainda havia certa inquietação para planejar de forma a atender as exigências do documento, devido às professoras ter como base para trabalhar um livro que deve ser concluído até o final do ano letivo, o que acaba por engessar a elaboração dos conteúdos a serem trabalhados com as crianças.

As professoras ainda contam com a colaboração de uma assessora orientadora para alinhar as atividades e depois desenvolver a metodologia em sala. O planejamento é realizado semanalmente às segundas-feiras por um período de quatro horas. As professoras da Educação Infantil preparam as aulas em conjunto e buscam se auxiliar relatando como foi o desenvolvimento das atividades propostas para a semana anterior, o que cada professora achou pertinente ou não. Segundo (Freire, 2005, p. 165),

Porque não discutir com os alunos a realidade concreta a que se deve associar a disciplina cujo conteúdo se ensina. Por vezes é através das discussões e demonstrações que as coisas se tornam palpável, aprende-se mais quando é possível constatar a realidade e visualizar o que se discute.

Neste dia foi decidido que a aula do estágio seria desenvolvida com o plano da professora titular, devido ao livro que os alunos precisam concluir até o final do ano letivo, para isso foi realizada uma análise do planejamento da aula da semana seguinte, quando foi realizada a aula do estágio. Os planos foram entregues para que a metodologia a ser trabalhada fosse desenvolvida. Devido à professora estar muito ocupada neste dia, apenas foi entregue o plano a ser realizado durante a aula no primeiro contato pessoal, voltando a entrar em contato no período noturno se desculpando pela falta de atenção e se colocando à disposição para o que fosse necessário.

\subsection{Observação da sala de aula}

O primeiro contato com os alunos foi no período da observação da sala de aula que ocorreu no turno vespertino em setembro de 2019, e talvez tenha sido um dos momentos mais impactantes do estágio por ser uma realidade completamente nova. A professora já havia conversado com a turma e informado que durante alguns dias eles teriam a presença de uma professora nova, as crianças receberam muito bem, trata-se de uma turma composta de crianças afáveis, almas delicadas, abraços voluntários, palavras doces, um aconchego para a alma. A organização da sala é dividida em duas fileiras, contendo dez cadeirinhas com mesas em cada fila, totalizando vinte alunos por sala, possui ar condicionado, decoração, e rotina interativa distribuída pelo interior da mesma, os acentos eram proporcionais ao tamanho das crianças além de contar com um quadro de vidro enorme.

Corroborando (Lopes, 2018, p. 2) à luz da perspectiva sócio histórica visualiza-se o desenvolvimento infantil com múltiplas possibilidades de interações das crianças nos espaços sociais que vivenciam, buscando compreende-lo, transforma-lo e se constituir enquanto sujeito social.

É pertinente que os espaços físicos e sociais da escola possam conversar com a realidade fora do muro e fora da sala de aula. As crianças são recebidas pela auxiliar da sala conforme vão chegando aos poucos, às $13 \mathrm{~h}$ a professora entra e por um 
momento que dura quinze minutos ela fica conversando com a turma para que se alguém estiver atrasado tenha tempo para chegar não perdendo assim conteúdo, depois ela conta os alunos e ambas os levam para o bebedouro para que possam tomar água e encher as garrafas, além de ir ao banheiro caso haja necessidade, ao retornar todos vão para o fundo da sala, se amontoam aos pés da professora e cantam uma infinidade de músicas que eles conhecem de cor, gesticulam e participaram com dedicação, esse processo dura uns quarenta minutos e, após sua realização as crianças vão para seus lugares para desenvolver a atividade planejada para aquele dia.

Ao escolherem o repertório e participarem com dedicação da coreografia, do canto, estão desenvolvendo saberes entre os pares.

É a curiosidade que torna possível um caminho para o aprendizado e que o papel do educador é provocar e instigar essa curiosidade por meio de atividades criativas, investigativas e lúdicas. Nesse contexto, o desafio, a curiosidade a experimentação, a resolução de problemas e a investigação devem existir em todos os processos escolares que envolvem aprendizes, desde a educação infantil à pós-graduação (Sinieghi, et al., 2020, p. 100).

A turma realiza uma atividade dirigida por aula, sendo esse o momento mais pertinente da aula, a professora iniciou a atividade colando as figuras no quadro, uva, anel, flor, mesa, dinossauro, vela, rato, tigre, joelho, goiaba e o sol e explicando que quando o sinal de adição (a professora utilizava o termo "mais") aparece indica que se deve acrescentar alguma coisa e quando aparece o de subtração (a professora utilizava o termo "menos") indica que se deve tirar alguma coisa, ao final do exercício a seguinte frase foi formada: "Eu adoro me divertir com jogos". A professora os motivava a colaborar na resolução da atividade, era um enigma que teriam que resolver. A atividade foi concluída após o intervalo, no entanto os alunos não pareciam entender o que tinham terminado de fazer, tendo em vista que o exercício era complexo até para um adulto, o que gerou certa frustração.

Após o término da atividade a professora conversou com os alunos sobre a primavera e às $16 \mathrm{~h}$ todos foram para o parque onde puderam desenvolver brincadeiras ao ar livre, às 16h50min a auxiliar levou as crianças da zona rural para pegar o ônibus e a professora ficou com as demais crianças até que todos fossem entregues aos pais. A professora convidou para participar de todos os momentos da aula, além de descrever o perfil de cada criança, as dificuldades familiares, as dificuldades de aprendizagem e foi solícita o tempo todo.

\subsection{A prática desenvolvida com a turma do PRÉ II}

O primeiro dia de regência aconteceu no dia 23/09/2019, a professora entrou fez as apresentações e comunicou à turma que nas duas primeiras horas de aula iriam fazer um passeio de ônibus para participar das atividades que o município estava proporcionando aos alunos naquele dia, fazia muito calor e ao todo foram seis turmas da Pré-escola para participar do evento. Ao chegar às crianças foram direcionadas a um salão para participar das atividades, o que não aconteceu tranquilamente, o ambiente estava muito barulhento, havia muitas crianças e foi necessário ficar cuidando dos alunos para não os perder.

As crianças participaram sem o pudor que acomete as pessoas mais velhas, se envolveram, socializaram com os visitantes, responderam aos questionamentos, e todos os professores dividiram esse momento com eles. Essa atividade foi dividida em vários setores e todos puderam participar, houve dança, contação de história, confecção de brinquedos, apresentação de filme para assistirem com os óculos 3D novos que eles haviam confeccionado e brincadeiras circenses, foram duas horas de muita atividade e diversão, às $15 \mathrm{~h}$ em ponto a turma foi reunida para o retorno à escola, ao chegar foram direto para o lanche.

Eles adoram esse momento, pois é quando podem se encontrar. Para (Stacciolli, 2018, p. 71) "não é fácil realizar uma escola onde as crianças estão bem porque sentem que há vida em todos os momentos". É imprescindível que seja mantido 
aquilo que foi ofertado desde o início, acompanhar e dar suporte as crianças num contexto geral, mas também na hora da alimentação, que para elas é um dos momentos mais importantes da rotina escolar. O munícipio respalda esse momento da comida com muito cuidado.

A secretaria de educação do município conta com uma nutricionista, a comida das crianças é balanceada, servem uma porção de arroz com feijão, um tipo de legume ou mais, uma carne, sopa e pão, é preciso acompanhar e ajudar a servi-los, a auxiliar de classe limpa a sujeira da mesa do refeitório. É um momento de interação onde todas as turmas da educação infantil de encontram sob o olhar atendo dos professores que interagem de forma a auxilia-los nas dificuldades.

"O contexto faz se sentir bem e quando há afinação emocional e relacional com os adultos e com seus colegas" (Staccioli, 2018, p. 61). Após terminar de se alimentar as crianças tomam água e retornam para a sala, nesse dia a atividade a ser desenvolvida com os alunos era a continuação do enigma proposto na aula anterior, às imagens foram novamente colocadas na lousa e os alunos foram motivados a dizer à letra que correspondia a cada figura, o que fizeram sabiamente.

Os alunos dessa turma já possuem domínio do alfabeto, foram cinco palavras que de acordo com as descobertas iam sendo colocadas na lousa, estátua, amarelinha, boliche e esconde-esconde, fizeram a leitura, estando sempre atenta a pronúncia correta de cada letra, indicando cada uma delas com os dedos para que fosse assimilada a oralidade com a letrinha correspondente, cada palavra foi lida mais de uma vez para ajudar na fixação. A professora entrou na sala e advertiu que precisavam dizer às crianças que aquela atividade estava relacionada aos jogos, porque naquela semana eles tinham que estudar jogos e os desenhar, pois era o que estava previsto na apostila que precisam seguir, o desejo era desenvolver a brincadeira, como uma das palavras era estátua, gostaria de ter proporcionado a brincadeira, assim como a amarelinha, o esconde-esconde o boliche. De acordo com (Teixeira, 2012) "A atividade lúdica é, portanto, uma das formas pelas quais a criança se apropria do mundo, e pela qual o humano entra em seu processo de constituição, enquanto sujeito histórico".

Aprender brincando é mais atrativo e faz com que a criança relacione o lúdico com o mundo real, além de permitir fugir do modo tradicionalista e exaustivo a que vem sendo trabalhado desde outrora, onde a criança sente motivação e alegria, brincando a criança desenvolve a imaginação, fundamenta afetos, explora habilidades e, na medida em que assume múltiplos papéis, fecunda competências cognitivas e interativas (Antunes, 2004). Na apostila eles tentaram desenhar os jogos, uma menina chamou muito atenção, no esconde-esconde ela desenhou um bonequinho, uma casinha e outro bonequinho atrás, ficou muito criativo. O planejamento a ser seguido foi estudado antes da aula para melhor conseguir passar para eles o que significa a palavra enigma, houve uma participação ávida da turma e a atividade foi concluída, logo em seguida os alunos pegaram uma apostila enorme que eles possuem onde registram as atividades diárias.

[...] Talvez a infância nos ajude a pensar na possibilidade de uma formação docente que seja infantil, uma formação de professores da infância. Uma formação de professor, que sendo infantil, não pretende representar, nem apresentar sua função, que não fecha questão sobre qualquer assunto, que não cria espaços onde verdades cristalizadas circulam, que não dita regras, nem modos de pensar e caminhos a seguir[...]. [...] Uma formação de professor que fuja dos modelos dados, de um devir definido, de uma infantilização docente. Que escape às rédeas da formação definida e faça surgir uma formação inusitada, que nos tira dos lugares comuns e previstos, para que assim possamos nos abrir aos atravessamentos, às afetações, aos acontecimentos, às experiências. Isso nos parece indicar algo mais potente do que pensar no alguém que pode saber ou pode aprender em um curso ou um programa de formação [...] (Chisté, 2018, p. 53).

Nos minutos restantes foi entregue aos alunos um saco de peças para montar no fundo da sala, foram construídos alguns edifícios e depois de concluído todos ajudaram a recolher os brinquedos antes de retornarem para suas casas.

No dia seguinte, 24/09/2019 a professora entrou alguns momentos antes para organizar a sala para a chegada dos alunos, após o término saiu deixando somente a auxiliar na sala. Nesse momento pode se perceber a rotina engessada que as crianças possuem, eles não aceitavam que uma vírgula fosse diferente do habitual, foram cantadas as mesmas músicas, pois 
não foi permitida a utilização de nada diferente. O planejamento para o dia era uma história a ser contada trabalhando valores, era a história de um burro, para tanto foi levada a figura de um burro desenhada em uma cartolina, para trabalhar as qualidades do burro e ir escrevendo-as sobre ele, para intermediar a próxima atividade que seria o acróstico, onde eles iriam descobrir suas qualidades com as letras do próprio nome. (Guimarães \& Arenari, 2018, p. 71) "os adultos ocupam um lugar de referência para a construção de novas formas de atuação por parte da própria criança”. Cabendo a este o dever de rever sua prática quantas vezes for necessário, para estar sempre pronto para acolher e orientar as crianças. Corroborando (Machado \& Rodrigues, 2018, p. 60) destacam a "necessidade de um profissional que conheça as especificidades do trabalho a ser desenvolvido nessa faixa etária e que conceba o cuidar e o educar como atos indissociáveis".

Ao iniciar a história, descrevendo as imagens, dizer quem contava a história, o nome do autor, escuta um burburinho enorme na sala, eles queriam que a história fosse apenas lida como a outra professora faz e não "refletir sobre a prática educacional, mediante a análise da realidade do ensino da leitura pausada, da troca de experiências. Estruturas que tornem possível a compreensão, a interpretação e a intervenção sobre a prática”, (Imbernón, 2010). Não foi possível refletir, desconstruir e reconstruir a história a partir do olhar de cada um. Se todos viam a história sob o mesmo olhar. A rotina restrita deixa as crianças mecânicas e a auxiliar da sala mantinha isso durante a aula, então tudo o que era desenvolvido pela professora teve que ser realizado exatamente igual. Quando (Luckesi, 2011, p. 165) afirma que, "o planejamento é um conjunto de ações coordenadas visando atingir os resultados previstos de forma mais eficiente". Entende-se que não foi possível desenvolver o planejamento como havia sido constituído, não houve oportunidades, e a inexperiência contribuiu para o fracasso da atividade.

Desde o primeiro contato com a turma um aluno chamou muito a atenção, de todos ele era o menos desenvolvido, mas muito querido, necessitava de auxílio na cadeira para desenvolver todas as atividades, mas o coração ia feliz porque era uma criança tão carinhosa e delicada, aquele que pertence ao professor, que é colocado embaixo do braço e amado, porque sabe que necessita de atenção e cuidado. (Vygotsky, 2001, p.63) "o comportamento do homem é formado por peculiaridades e condições biológicas e sociais do seu crescimento". Daí a importância do convívio com outras crianças. O dever de promover a inserção desta para que este processo seja menos doloroso e possa propiciar o desenvolvimento cognitivo.

A atividade foi explicada, o nome de todos foi colocado na lousa e então foi solicitado que falassem as características do colega, exemplo: ISABELLA, uma qualidade com cada letra do nome da menina, mas eles ainda não conhecem os adjetivos, pois não havia sido trabalhado anteriormente, com a colaboração da professora, da auxiliar e com a deles que foram sendo instigada, a atividade foi concluída, sem sucesso, porque eles não conseguiram compreender em uma única aula o que são adjetivos, então a cada característica que era revelada de um colega, os demais colegas que tinham as letras correspondentes iam preenchendo o seu acróstico, não foi uma atividade de fácil desenvolvimento, e as crianças não se sentiram motivados, era algo que deveria ter sido trabalhado com vídeos, histórias, conversas, antes de ser apresentado em sala. A tarde transcorreu com a mesma rotina dos dias anteriores, julgando que a rotina seja necessária para a sala de aula, acreditase que esta não necessariamente precisa estar em evidência, porque tudo se torna restritivo, não se pode mudar uma vírgula, está impregnado na vida escolar daquelas crianças, o ritual metódico é exaustivo.

Ao final da aula foi levada uma atividade diferenciada para as crianças, que foi demonstrada com a auxiliar para que eles compreendessem, na entrada da sala foram colocadas três figuras, um coração, uma nota musical, duas mãozinhas abertas, e uma música de fundo com uma letra bem bonita, quem desejasse um abraço de despedida deveria bater com as mãos no coração, quem escolhesse a nota musical, fazia uma dancinha, e as palminhas indicavam um toque das mãos com a professora, após a saudação eles recebiam uma lembrancinha e iam aguardar na fila para seguir para o parque, uma forma de socializar, despedir e levar ao menos uma atividade que estivesse alheia ao planejamento da professora regente. 
Apenas duas crianças apertaram as mãos, os demais foram envolvidos em muitos abraços apertados, quando chegou o menininho que possui mais dificuldades, ele escolheu o abraço e o fez com tanto carinho, foi um abraço tão prolongado, colou a testa na professora e assim permaneceu, a professora e a auxiliar romperam em lágrimas, foi um momento mágico de muito amor. Esse amor é nítido entre a professora titular da sala e os alunos, ela se dirige a eles com muita dedicação e é recíproco. Os educadores, apesar das suas dificuldades, são insubstituíveis, porque a gentileza, a solidariedade, a tolerância, a inclusão, os sentimentos altruístas, enfim todas as áreas da sensibilidade não podem ser ensinadas por máquinas, e sim por seres humanos (Cury, 2003).

Ao término do estágio alguns pontos foram observados, a sala possui alunos com características distintas, tem alunos que oralmente se desenvolvem muito bem, mas na grafia estão penalizados, alunos que compreendem as atividades e respondem a apostila sem o auxílio do professor, também tem aqueles que sabem, mas não avançam, ficando no aguardo do professor e também tem os que não possuem motivação, estão sempre alheios em um mundo que pertence somente a eles.

\subsection{Visita a creche criança feliz}

Para abranger todas as etapas da Educação o estágio também foi realizado na Creche para conhecimento da dinâmica e da realidade dessa etapa, o que ocorreu em setembro de 2019. Primeiramente foi realizado o acompanhamento e observação do planejamento das professoras do berçário e do maternal, o planejamento é realizado pelas professoras com base no Documento Referência (DRC), embora dividam o mesmo espaço os planejamentos são individuais, pois as professoras observaram que os alunos possuem características distintas e, o que se aplica a determinadas crianças pode não ser pertinente para as demais, o planejamento também compreende uma atividade dirigida por aula e essa atividade é planejada de acordo com o tema da semana, nesse dia o planejamento abrangeu a primavera.

No dia 30 de setembro, no período vespertino, aconteceu à observação no berçário II, foi apaixonante, ao chegar à professora e a auxiliar já estavam em sala, elas entram 12h45min, para receber as crianças. A creche é um espaço recémconstruído e possui oito salas de aula além de inúmeros departamentos para atender as demais necessidades, como sala de professores, sala de vídeo, cozinha, secretaria, sala da direção, sala da coordenação, recepção, um rol enorme com refeitório e solar.

É um espaço lindo, as salas de aula possuem uma recepção com nichos para guardar os pertences de todos, uma sala com uma pia enorme, onde ficam as mamadeiras, copos, umidificador de ar, aparelho de som, tatame e colchões, uma sala onde as crianças dormem, outra salinha onde se vestem e um banheiro adequado a eles e também uma varanda enorme onde eles podem pegar um solzinho ao final do dia, todas as salas possuem o mesmo padrão.

Após a chegada das crianças essas são levadas ao tatame para cantarem algumas músicas que eles adoram, fazem gestos divertem-se, em seguida fazem uma atividade dirigida, nesse dia foram trabalhado com as quatro cores primárias, a atividade se desenvolveu da seguinte maneira: a professora pintou quatro copos descartáveis, nas cores, verde, amarelo, vermelho e azul, passou estes copos por um barbante que amarrou na maçaneta de duas portas, chamou um aluno e disse para levar o copo vermelho até a outra dimensão e assim sucessivamente até transportarem os quatro copos, nesse momento às características dos alunos ficaram perceptíveis, uma aluna levou os copinhos um por vez até a outra dimensão exatamente como a professora havia pedido, outro levou todos de uma vez, teve aquele que levava e trazia de volta, mas um aluno em especial chamou muito atenção, enquanto os colegas faziam a atividade ele se envolvia, quando a professora o chamou ele não esboçou nenhuma reação, parecia não saber que a professora falava com ele, então discretamente foi perguntado a auxiliar se ele ouvia e ela disse que sim, mas isso gerou uma enorme inquietação, pois a impressão é que ele não fazia ideia de que existe sons, percebe -se então que ele ainda não fala e todos possuem idade que vai dos dois anos a dois anos e seis meses, e os demais falam. 
Falar da creche ou da educação infantil é muito mais do que falar de uma instituição, de suas qualidades e defeitos, da sua necessidade social ou da sua importância educacional. É falar da criança. De um ser humano, pequenino, mas exuberante de vida (Machado, 2009).

Terminada essa atividade os alunos foram para o café da tarde, onde é realizado primeiramente a higienização das mãos, em seguida é servido um pão com suco natural, eles fazem uma bagunça organizada, uns comem, outros brincam e alguns choram, a auxiliar preparou algumas mamadeiras porque alguns ainda mamam.

Após o lanche todos retornaram a sala e foram direto para os colchões, na salinha de dormir um detalhe chamou atenção, apenas os colchões que os pais mandam lençóis são cobertos, os demais deitam no colchão puro, algumas desigualdades sociais, no atual contexto social, cabe às instituições de ensino superior um papel garantindo uma sólida formação teórica, criando condições para a constituição profissionais capazes de atuar em vários campos do saber, alicerçada em convicções humanas e comprometida na busca por uma sociedade menos desigual, que ao mesmo tempo torna o estudante corresponsável por sua própria formação e valorização profissional (Gomes, 2009), quando todos haviam dormido a professora se sentou a porta para que ninguém acordasse e saísse do quarto e ficou trabalhando nas anotações, após uma hora e alguns minutos eles foram acordados e levados para o refeitório para outra refeição que eles chamam de jantar, neste jantar foi servido uma porção de arroz, feijão, carne, salada e fruta.

Por fim, ao término do jantar são levadas ao banho, as roupinhas são tiradas no tatame e só de fralda eles fazem uma filha no banheiro, a professora dá o banho e a auxiliar veste as roupas e escova os cabelos, enquanto cuida da porta para ver qual pai já chegou para preparar o filho dele para ir para casa, esse momento é bem corrido, se ao término do banho algum pai ainda não chegou eles ficam no tatame e depois vão ao parque.

No momento do parque a professora falou sobre aquele aluno do qual foi levantado suspeita e disse que para ela ele não ouve e que foi observado que ele não abraça ninguém por frente, ele só aceita abraço se este estiver de costas e que havia perdido noites de sono sem saber como ia abordar os pais, mas que ao falar com eles, ambos compreenderam tranquilamente, quando a mãe chegou e o chamou pelo nome, ele não percebeu estava sendo chamando, imediatamente a professora trocou um olhar, confirmando a conversa que havia acontecido antes, segundo Pimenta e Lima (2006) o estágio é atividade de conhecimento, fundamentação, diálogo e intervenção na realidade, mas a mãe parece não perceber que ele não ouve, e talvez este não fale porque não houve.

(Pimenta \& Lima, 2004) dizem que, somente a observação não garante a aprendizagem profissional, pois esta não permite ao graduando pensar, estudar a realidade e refletir, aspectos fundamentais à construção do conhecimento profissional, portanto no dia primeiro de outubro foi realizada à regência para a turma do maternal I, era uma turma bem menor, porém, mais agitada.

A professora responsável pela turma estava de atestado médico e no dia quem estava com os alunos era a professora substituta, as crianças eram maiores, nervosas, eles não falavam e sim gritavam, pulavam tudo ao mesmo tempo e a professora estava esgotada, apesar de ser recém-formada ela contou que está no limite, desencantada com a profissão, que as crianças não respeitam, não produzem só fazem o que querem, ela estava realmente desmotivada. A turma em questão é uma turma que já possui autonomia, eles já conseguem resolver muita coisa sozinha, tem sempre àquele que ainda necessita de maior atenção, mas são independentes num contexto geral.

Apesar de já possuir mesinhas com cadeiras na sala nesse dia a atividade foi realizada no chão, a professora fez uma mistura de cores com o pincel na mãozinha deles e fez duas marcas numa folha de sulfite que foi levada para secar, na aula do dia seguinte aquilo se tornaria uma borboleta, os outros momentos foram utilizados para brincadeiras no parque porque tiveram problemas com o sistema de energia e estava insuportável permanecer na sala devido ao calor, no final do dia a professora 
auxiliar pegou um nécessaire com alguns itens e escovou o cabelo dos meninos e a outra professora fez algumas tranças nas meninas, e todos foram para casa arrumadinha.

Na saída a professora precisou conversar com duas das mães, pois durante o parque duas crianças se acidentaram, uma cortou os lábios e a outra ficou com os dentes do outro desenhado logo abaixo dos olhos, devido à trombada que deram, a mãe do menino entendeu tranquilamente, a mãe da menina ficou nítido que não gostou do ocorrido, mas foi um acidente sem pretensão alguma de ambas as partes. Mas a professora foi firme com as palavras ao informar o acontecido, a escola consegue resolver grande parte dos problemas de ensino, mas não podem controlar os acontecimentos que todos estão sujeitos a enfrentar.

\section{Conclusão}

De acordo com (Pacifico, et. al, 2020), a partir das leituras dos relatórios, foi possível perceber que o Estágio Supervisionado em Educação Infantil contribuiu, significativamente, para a formação dos estagiários, futuros docentes da etapa da Educação Infantil, é notório o avanço e amadurecimento dos alunos quanto ao planejar tempos, espaços, materiais, atividades, desenvolver e avaliar práticas pedagógicas ao longo do estágio, aspectos explicitados nos relatórios apresentados.

Dentre os estágios realizados durante o curso de Pedagogia, esse foi o que mais deixou uma lacuna aberta, uma sensação de que podia ter sido melhor, diferente, a limitação que se teve em trabalhar com o planejamento da escola, quando o semestre inteiro de aula na faculdade foi pautado sobre elaboração de planejamento, o sentimento de que o que foi trabalhado não acrescentou em nada a vida das crianças, a falta de autonomia que se teve em sala de aula devido a rotina considerada restritiva.

Embora exista uma relação entre o plano de ensino da disciplina e os relatórios analisados, ainda persiste uma grande distância entre a formação oferecida no âmbito acadêmico e a prática das instituições. Isso, ao contrário de oferecer um descrédito à formação, demonstra uma necessidade de melhor preparo e espaço para as discussões acerca da Educação Infantil nos cursos de formação de docentes, (Lira, et. al, 2020).

Fica o aprendizado de que o amor das crianças é incondicional e que elas estão abertas a doar e a receber muitíssimo amor, que é na escola que eles suprem o amor que lhes falta, pois a maioria possuem famílias desestruturadas por diversos motivos, que na professora regente eles encontram parte do afeto que necessitam, pois esta doa muito amor, que a aula será um diferencial quando estiver voltada para a realidade e a compreensão que eles possuem do cotidiano, o amadurecimento virá com o tempo e o planejamento que caracteriza a parte primordial da aula deverá estar voltada para a realidade do aluno.

É nítido que o professor precisará sempre de um excelente planejamento para conseguir atender a realidade dos alunos, que esse planejamento deve ser elaborado com o aluno e para o aluno, este deve ser de possível compreensão, não se preocupando em saber tudo, mas o que se sabe saber por inteiro, abordar uma metodologia que seja concreta, e que seus alunos serão de poder aquisitivos diferentes e conhecimentos distintos, o nivelamento propriamente não existe, pois os níveis de desenvolvimentos são singulares e este aprende paulatinamente e o tempo de uma criança se difere do tempo da outra. É do professor o papel de adaptar o planejamento às dificuldades de seus alunos, o tempo ocioso deve ser preenchido com atividades que sejam relevantes, não apenas ocupação de tempo.

Evidenciou que o domínio da sala de aula se conquista com postura e respeito, e acima de tudo ouvir o que o aluno tem a dizer, as crianças estão sempre querendo dizer alguma coisa e não tem ninguém para ouvir preocupado em completar as páginas do livro até o final do dia, a vida escolar do aluno não está dicotomizada da vida que este tem em casa.

Assim, com essas experiências se confirma que o conhecimento presente na teoria precisa dialogar com a prática e que a criança aprende por meio do que gosta, ou seja, a brincadeira a qual é essencial na vida da mesma. Tanto a etapa de observação como a de participação foram essenciais no estágio, mas é na etapa de atuação que se adquiriu conhecimentos e 
experiências diversas, as quais serão levadas como experiências positivas para quando for assumir uma turma da Educação Infantil. Faz-se necessário mais estudo sobre as experiências de estágio para que os acadêmicos possam ter bases como referência da prática do estágio direto em sala de aula.

Como trabalhos futuros sugere-se que desenvolvam mais trabalhos de estágio supervisionado, sugestão esta, pautada na dificuldade encontrada para fundamentar pesquisas com autores atuais, dos últimos três anos visando auxiliar futuros acadêmicos de Licenciaturas, que precisam de embasamento cada vez mais recente.

\section{Referências}

Antunes, C. (2004). Educação infantil: prioridade imprescindível. Vozes.

Chizzotti, A. (2014). Pesquisa qualitativa em ciências humanas e sociais. (6a ed.), Vozes.

Chisté, B. S. O que pode a infância na formação docente? (2018). In: Pacífico, Machado, E. M. A. Rodrigues, A. L. de O. In: Pacífico, J. M. Pimenta, J. S. Chisté, B. dos S. Neves, J. G. Zibetti, M. L. T. (Orgs). Docência na Educação Infantil: experiências e práticas em formação continuada. Jundiaí [SP]: Paco.

Cury, A. J. (2003). Pais brilhantes, professores fascinantes. Sextante.

Freire, P. (2005). Pedagogia da autonomia: saberes necessários à prática educativa. (3a ed.) Paz e Terra.

Gil, A. C. (2010). Como elaborar projetos de pesquisa. (5a ed.), Atlas.

Gomes, M. de O. (2009). Formação de professores na educação infantil. Cortez.

Guimarães, D. \& de O Arenari, R. (2018). Na creche, cuidados corporais, afetividade e dialogia. Educação em Revista, 34, 01-18, https://doi.org/10.1590/0102-4698186909.

Hargreaves, A. (2002). Aprendendo a mudar: o ensino para além dos conteúdos e da padronização. Artmed.

Imbernón, F. (2010). Formação continuada de professores. Artmed.

Imbernón, F. (2010). Formação continuada de professores. Artmed.

Imbernón, F. (2010). Formação docente e profissional: formar-se para a mudança e a incerteza. (8a ed.), Cortez.

Lakatos, E. M. \& Marconi, M. de A. (2001). Fundamentos da metodologia cientifica. (4a ed.), Atlas.

Lira, A. C. M. Dominico, E. Silva, K. de O. \& Saito, H. T. I. (2020). Estágio supervisionado na Educação Infantil: desafios e contribuições para a formação inicial de professores. Conjectura: Filos. Educ., Caxias do Sul, RS, Ahead of Print, 25, e020012.

Lopes, C. A. O. (2021). A iniciação científica na Educação Infantil, possibilidades pedagógicas. In: Congresso Nacional De Educação - CONEDU, 5., 2018, Recife. Anais [...].

Luckesi, C. C. (2014). Avaliação da aprendizagem escolar: estudos e proposições. Cortez editora.

Machado, M. C. G., \& Pascoal, J. D. (2009). A história da educação infantil no Brasil: avanços, Retrocessos e desafios dessa modalidade educacional. Revista HISTEDBR On-line, 33, 78-95. Obtido de http://www.histedbr.fae.unicamp.br/revista/edicoes/33/art05_33.pdf.

Pacifico, J. M. Dantas, R. de L. Brandt, A. de S. \& Rodrigues, M. (2020). Estágio supervisionado na educação infantil: relatos e reflexões. Educação em Foco, 23(39), 127-148

Pimenta, S. G., \& Lima, M. S. L. (2006). Estágio e docência. Cortez.

Pimenta, S. G., \& Lima, M. S. L. (2004). Estágio e Docência. Cortez.

Sinieghi, A. L. M. L. et al. (2020). Construção de foguete de água na Educação Infantil: possibilidades de iniciação científica. Revista Principia - Divulgação Científica e Tecnológica do IFPB, (50), 99-108. http://dx.doi.org/10.18265/1517-0306a2020v1n50p99-108.

Staccioli, G. (2018). As rotinas: de hábitos estéreis a ações férteis. Revista Linhas, 19(40), 54-73, 10.5965/1984723819402018054.

Texeira, S. R. de O. (2012). Jogos, brinquedos, brincadeiras e brinquedoteca: implicações no processo de aprendizagem e desenvolvimento. (2a ed.), Wak.

Vasconcellos, C. S. (2000). Planejamento: Projeto de Ensino- Aprendizagem e projeto Político Pedagógico. (9a ed.), Libertad.

Vygotsky, L. S. (2001). Psicologia pedagógica. Martins fontes. 